\title{
Diretrizes e normas regulamentadoras de pesquisas envolvendo seres humanos
}

Conselho Nacional de Saúde - Resolução 196/96

- Pesquisa

- Qualificação do pesquisador

- Consentimento informado

- Comitê de Ética em Pesquisa - CEP

- Riscos e beneficios

- Projeto de pesquisa

- Comissão Nacional de Ética em Pesquisa CONEP

\section{TEXTO DA RESOLUÇÃO}

O Conselho Nacional de Saúde, no uso da competência que lhe é outorgada pelo Decreto $\mathrm{n}^{\circ} 93.933$ de 14 de janeiro de 1987, resolve:

Aprovar as seguintes diretrizes e normas regulamentadoras de pesquisas envolvendo seres humanos:

\section{I - Preâmbulo}

A presente Resolução fundamenta-se nos principais documentos internacionais que emanaram declarações e diretrizes sobre pesquisas que envolvem seres humanos: o Código de Nuremberg (1947), a Declaração dos Direitos do Homem (1948), a Declaração de Helsinque (1964 e suas versões posteriores de 1975, 1983 e 1989), o Acordo Internacional sobre Direitos Civis e Políticos (ONU, 1966, aprovado pelo Congresso Nacional Brasileiro em 1992), as Propostas de Diretrizes Éticas Internacionais para Pesquisas Biomédicas Envolvendo Seres Humanos (CIOMS/OMS 1982 e 1993) e as Diretrizes Internacionais para Revisão Ética de Estudos Epidemiológicos (CIOMS, 1991). Cumpre as disposições da Constituição da República Federativa do Brasil de 1988 e da legislação brasileira correlata: Código de Direitos do Consumidor, Código Civil e Código Penal, Estatuto da Criança e do Adolescente, Lei Orgânica da Saúde 8.080, de 19/09/90 (dispõe sobre as condições de atenção à saúde, a organização e o funcionamento dos serviços correspondentes), Lei 8.142, de 28/12/90 (participação da comunidade na gestão do Sistema Único de Saúde), Decreto 99.438, de 07/08/90 (organização e atribuições do Conselho Nacional de Saúde), Decreto 98.830, de 15/01/90 (coleta por estrangeiros de dados e materiais científicos no Brasil), Lei 8.489, de 18/11/92, e Decreto 879, de 22/07/93 (dispõem sobre retirada de tecidos, órgãos e outras partes do corpo humano com fins humanitários e científicos), Lei 8.501, de 30/11/92 (utilização de cadáver), Lei 8.974, de 05/01/95 (uso das técnicas de engenharia genética e liberação no meio ambiente de organismos geneticamente modificados), Lei 9.279, de 14/05/96 (regula direitos e obrigações relativos à propriedade industrial), e outras.

Esta Resolução incorpora, sob a ótica do indivíduo e das coletividades os quatro referenciais básicos da bioética: autonomia, não maleficência, beneficência e justiça, entre outros, e visa assegurar os direitos e deveres que dizem respeito à comunidade científica, aos sujeitos da pesquisa e ao Estado.

O caráter contextual das considerações aqui desenvolvidas implica em revisões periódicas desta Resolução, conforme necessidades nas áreas tecnocientífica e ética.

Ressalta-se, ainda, que cada área temática de investigação e cada modalidade de pesquisa, além de respeitar os princípios emanados deste texto, deve cumprir com as exigências setoriais e regulamentações específicas.

\section{II - Termos e definições}

A presente Resolução, adota no seu âmbito as seguintes definições:

II.1 - Pesquisa - classe de atividades cujo objetivo é desenvolver ou contribuir para o conhecimento generalizável. O conhecimento generalizável consiste em teorias, relações ou princípios ou no acúmulo de informações sobre as quais estão baseados, que possam ser corroborados por métodos científicos aceitos de observação e inferência.

II.2 - Pesquisa envolvendo seres humanos - pesquisa que, individual ou coletivamente, envolva o ser humano de forma direta ou indireta, em sua totalidade ou partes dele, incluindo o manejo de informações ou materiais.

II.3 - Protocolo de pesquisa - documento contemplando a descrição da pesquisa em seus aspectos fundamentais, informações relativas ao sujeito da pesquisa, à qualificação dos pesquisadores e à todas as instâncias responsáveis.

II.4 - Pesquisador responsável - pessoa responsável pela coordenação e realização da pesquisa e pela integridade e bem-estar dos sujeitos da pesquisa. 
II.5 - Instituição de pesquisa - organização, pública ou privada, legitimamente constituída e habilitada na qual são realizadas investigações científicas.

II.6 - Promotor - indivíduo ou instituição, responsável pela promoção da pesquisa.

II.7 - Patrocinador - pessoa física ou jurídica que apoia financeiramente a pesquisa.

II.8 - Risco da pesquisa - possibilidade de danos à dimensão física, psíquica, moral, intelectual, social, cultural ou espiritual do ser humano, em qualquer fase de uma pesquisa e dela decorrente.

II.9 - Dano associado ou decorrente da pesquisa - agravo imediato ou tardio, ao indivíduo ou à coletividade, com nexo causal comprovado, direto ou indireto, decorrente do estudo científico.

II.10 - Sujeito da pesquisa - é o(a) participante pesquisado(a), individual ou coletivamente, de caráter voluntário, vedada qualquer forma de remuneração.

II.11 - Consentimento livre e esclarecido - anuência do sujeito da pesquisa e/ou de seu representante legal, livre de vícios (simulação, fraude ou erro), dependência, subordinação ou intimidação, após explicação completa e pormenorizada sobre a natureza da pesquisa, seus objetivos, métodos, benefícios previstos, potenciais riscos e o incômodo que esta possa acarretar, formulada em um termo de consentimento, autorizando sua participação voluntária na pesquisa.

II.12 - Indenização - cobertura material, em reparação a dano imediato ou tardio, causado pela pesquisa ao ser humano a ela submetida.

II.13 - Ressarcimento - cobertura, em compensação, exclusiva de despesas decorrentes da participação do sujeito na pesquisa.

II.14 - Comitês de Ética em Pesquisa - CEP - colegiados interdisciplinares e independentes, com "múnus público", de caráter consultivo, deliberativo e educativo, criados para defender os interesses dos sujeitos da pesquisa em sua integridade e dignidade e para contribuir no desenvolvimento da pesquisa dentro de padrões éticos.

II.15 - Vulnerabilidade - refere-se a estado de pessoas ou grupos, que por quaisquer razões ou motivos, tenham a sua capacidade de autodeterminação reduzida, sobretudo no que se refere ao consentimento livre e esclarecido.

II.16 - Incapacidade - refere-se ao possível sujeito da pesquisa que não tenha capacidade civil para dar o seu consentimento livre e esclarecido, devendo ser assistido ou representado, de acordo com a legislação brasileira vigente.

\section{III - Aspectos éticos da pesquisa envolvendo seres humanos}

As pesquisas envolvendo seres humanos devem atender às exigências éticas e científicas fundamentais.

III.1 - A eticidade da pesquisa implica em:

a) consentimento livre e esclarecido dos indivíduos-alvo e a proteção a grupos vulneráveis e aos legalmente incapazes (autonomia). Neste sentido, a pesquisa envolvendo seres humanos deverá sempre tratá-lo em sua dignidade, respeitá-lo em sua autonomia e defendê-lo em sua vulnerabilidade;

b) ponderação entre riscos e beneficios, tanto atuais como potenciais, individuais ou coletivos (beneficência), comprometendo-se com o máximo de beneficios e o mínimo de danos e riscos;

c) garantia de que danos previsíveis serão evitados (não maleficência);

d) relevância social da pesquisa com vantagens significativas para os sujeitos da pesquisa e minimização do ônus para os sujeitos vulneráveis, o que garante a igual consideração dos interesses envolvidos, não perdendo o sentido de sua destinação sócio-humanitária (justiça e eqüidade).

III.2 - Todo procedimento de qualquer natureza envolvendo o ser humano, cuja aceitação não esteja ainda consagrada na literatura científica, será considerado como pesquisa e, portanto, deverá obedecer às diretrizes da presente Resolução. Os procedimentos referidos incluem entre outros, os de natureza instrumental, ambiental, nutricional, educacional, sociológica, econômica, física, psíquica ou biológica, sejam eles farmacológicos, clínicos ou cirúrgicos e de finalidade preventiva, diagnóstica ou terapêutica.

III.3 - A pesquisa em qualquer área do conhecimento, envolvendo seres humanos deverá observar as seguintes exigências:

a) ser adequada aos princípios científicos que a justifiquem e com possibilidades concretas de responder a incertezas;

b) estar fundamentada na experimentação prévia realizada em laboratórios, animais ou em outros fatos científicos;

c) ser realizada somente quando o conhecimento que se pretende obter não possa ser obtido por outro meio;

d) prevalecer sempre a probabilidade dos beneficios esperados sobre os riscos previsiveis; 
e) obedecer a metodologia adequada. Se houver necessidade de distribuição aleatória dos sujeitos da pesquisa em grupos experimentais e de controle, assegurar que, a priori, não seja possivel estabelecer as vantagens de um procedimento sobre outro através de revisão de literatura, métodos observacionais ou métodos que não envolvam seres humanos;

f) ter plenamente justificada, quando for o caso, a utilização de placebo, em termos de não maleficência e de necessidade metodológica;

g) contar com o consentimento livre e esclarecido do sujeito da pesquisa e/ou seu representante legal;

h) contar com os recursos humanos e materiais necessários que garantam o bem-estar do sujeito da pesquisa, devendo ainda haver adequação entre a competência do pesquisador e o projeto proposto;

i) prever procedimentos que assegurem a confidencialidade e a privacidade, a proteção da imagem e a não estigmatização, garantindo a não utilização das informações em prejuízo das pessoas e/ou das comunidades, inclusive em termos de auto-estima, de prestígio e/ou econômico-financeiro;

j) ser desenvolvida preferencialmente em individuos com autonomia plena. Indivíduos ou grupos vulneráveis não devem ser sujeitos de pesquisa quando a informação desejada possa ser obtida através de sujeitos com plena autonomia, a menos que a investigação possa trazer beneficios diretos aos vulneráveis. Nestes casos, o direito dos indivíduos ou grupos que queiram participar da pesquisa deve ser assegurado, desde que seja garantida a proteção à sua vulnerabilidade e incapacidade legalmente definida;

1) respeitar sempre os valores culturais, sociais, morais, religiosos e éticos, bem como os hábitos e costumes quando as pesquisas envolverem comunidades;

m) garantir que as pesquisas em comunidades, sempre que possível, traduzir-se-ão em beneficios cujos efeitos continuem a se fazer sentir após sua conclusão. O projeto deve analisar as necessidades de cada um dos membros da comunidade e analisar as diferenças presentes entre eles, explicitando como será assegurado o respeito às mesmas;

n) garantir o retorno dos beneficios obtidos através das pesquisas para as pessoas e as comu- nidades onde as mesmas forem realizadas. Quando, no interesse da comunidade, houver beneficio real em incentivar ou estimular mudanças de costumes ou comportamentos, o protocolo de pesquisa deve incluir, sempre que possivel, disposições para comunicar tal beneficio às pessoas e/ou comunidades;

o) comunicar às autoridades sanitárias os resultados da pesquisa sempre que os mesmos puderem contribuir para a melhoria das condições de saúde da coletividade, preservando, porém, a imagem e assegurando que os sujeitos da pesquisa não sejam estigmatizados ou percam a auto-estima;

p) assegurar aos sujeitos da pesquisa os beneficios resultantes do projeto, seja em termos de retorno social, acesso aos procedimentos, produtos ou agentes da pesquisa;

q) assegurar aos sujeitos da pesquisa as condições de acompanhamento, tratamento ou de orientação, conforme o caso, nas pesquisas de rastreamento; demonstrar a preponderância de beneficios sobre riscos e custos;

r) assegurar a inexistência de conflito de interesses entre o pesquisador e os sujeitos da pesquisa ou patrocinador do projeto;

s) comprovar, nas pesquisas conduzidas do exterior ou com cooperação estrangeira, os compromissos e as vantagens, para os sujeitos das pesquisas e para o Brasil, decorrentes de sua realização. Nestes casos deve ser identificado o pesquisador e a instituição nacionais co-responsáveis pela pesquisa. O protocolo deverá observar as exigências da Declaração de Helsinque e incluir documento de aprovação, no país de origem, entre os apresentados para avaliação do Comitê de Ética em Pesquisa da instituição brasileira, que exigirá o cumprimento de seus próprios referenciais éticos. Os estudos patrocinados do exterior também devem responder às necessidades de treinamento de pessoal no Brasil, para que o País possa desenvolver projetos similares de forma independente;

t) utilizar o material biológico e os dados obtidos na pesquisa exclusivamente para a finalidade prevista no seu protocolo;

u) levar em conta, nas pesquisas realizadas em mulheres em idade fértil ou em mulheres grávidas, a avaliação de riscos e beneficios e as eventuais interferências sobre a fertilidade, a gravidez, o embrião ou o feto, o trabalho de parto, o puerpério, a lactação e o recém-nascido; 
v) considerar que as pesquisas em mulheres grávidas devem ser precedidas de pesquisas em mulheres fora do período gestacional, exceto quando a gravidez for o objetivo fundamental da pesquisa;

x) propiciar, nos estudos multicêntricos, a participação dos pesquisadores que desenvolverão a pesquisa na elaboração do delineamento geral do projeto; e

z) descontinuar o estudo somente após análise das razões da descontinuidade pelo CEP que a aprovou.

\section{IV - Consentimento livre e esclarecido}

O respeito devido à dignidade humana exige que toda pesquisa se processe após consentimento livre e esclarecido dos sujeitos, indivíduos ou grupos que por si e/ou por seus representantes legais manifestem a sua anuência à participação na pesquisa.

IV.1 - Exige-se que o esclarecimento dos sujeitos se faça em linguagem acessivel e que inclua necessariamente os seguintes aspectos:

a) a justificativa, os objetivos e os procedimentos que serão utilizados na pesquisa;

b) os desconfortos e riscos possiveis e os beneficios esperados;

c) os métodos alternativos existentes;

d) a forma de acompanhamento e assistência, assim como seus responsáveis;

e) a garantia de esclarecimento, antes e durante o curso da pesquisa, sobre a metodologia, informando a possibilidade de inclusão em grupo controle ou placebo;

f) a liberdade do sujeito se recusar a participar ou retirar seu consentimento, em qualquer fase da pesquisa, sem penalização alguma e sem prejuízo ao seu cuidado;

g) a garantia do sigilo que assegure a privacidade dos sujeitos quanto aos dados confidenciais envolvidos na pesquisa;

h) as formas de ressarcimento das despesas decorrentes da participação na pesquisa; e

i) as formas de indenização diante de eventuais danos decorrentes da pesquisa.

IV.2 - O termo de consentimento livre e esclarecido obedecerá aos seguintes requisitos:

a) ser elaborado pelo pesquisador responsável, expressando o cumprimento de cada uma das exigências acima;

b) ser aprovado pelo Comitê de Ética em Pesquisa que referenda a investigação; c) ser assinado ou identificado por impressão dactiloscópica, por todos e cada um dos sujeitos da pesquisa ou por seus representantes legais; e

d) ser elaborado em duas vias, sendo uma retida pelo sujeito da pesquisa ou por seu representante legal e uma arquivada pelo pesquisador.

IV.3 - Nos casos em que haja qualquer restrição à liberdade ou ao esclarecimento necessários para o adequado consentimento, deve-se ainda observar:

a) em pesquisas envolvendo crianças e adolescentes, portadores de perturbação ou doença mental e sujeitos em situação de substancial diminuição em suas capacidades de consentimento, deverá haver justificação clara da escolha dos sujeitos da pesquisa, especificada no protocolo, aprovada pelo Comitê de Ética em Pesquisa, e cumprir as exigências do consentimento livre e esclarecido, através dos representantes legais dos referidos sujeitos, sem suspensão do direito de informação do indivíduo, no limite de sua capacidade;

b) a liberdade do consentimento deverá ser particularmente garantida para aqueles sujeitos que, embora adultos e capazes, estejam expostos a condicionamentos específicos ou à influência de autoridade, especialmente estudantes, militares, empregados, presidiários, internos em centros de readaptação, casas-abrigo, asilos, associações religiosas e semelhantes, assegurando-lhes a inteira liberdade de participar ou não da pesquisa, sem quaisquer represálias;

c) nos casos em que seja impossivel registrar o consentimento livre e esclarecido, tal fato deve ser devidamente documentado com explicação das causas da impossibilidade e parecer do Comitê de Ética em Pesquisa;

d) as pesquisas em pessoas com o diagnóstico de morte encefálica só podem ser realizadas desde que estejam preenchidas as seguintes condições:

- documento comprobatório da morte encefálica (atestado de óbito);

- consentimento explícito dos familiares e/ou do responsável legal, ou manifestação prévia da vontade da pessoa;

- respeito total à dignidade do ser humano sem mutilação ou violação do corpo;

- sem ônus econômico financeiro adicional à família;

- sem prejuízo para outros pacientes aguardando internação ou tratamento; 
- possibilidade de obter conhecimento científico relevante, novo e que não possa ser obtido de outra maneira;

e) em comunidades culturalmente diferenciadas, inclusive indígenas, deve-se contar com a anuência antecipada da comunidade através dos seus próprios líderes, não se dispensando, porém, esforços no sentido de obtenção do consentimento individual;

f) quando o mérito da pesquisa depender de alguma restrição de informações aos sujeitos, tal fato deve ser devidamente explicitado e justificado pelo pesquisador e submetido ao Comitê de Ética em Pesquisa. Os dados obtidos a partir dos sujeitos da pesquisa não poderão ser usados para outros fins que os não previstos no protocolo e/ou no consentimento.

\section{V - Riscos e benefícios}

Considera-se que toda pesquisa envolvendo seres humanos envolve risco. O dano eventual poderá ser imediato ou tardio, comprometendo o indivíduo ou a coletividade.

V.1 - Não obstante os riscos potenciais, as pesquisas envolvendo seres humanos serão admissiveis quando:

a) oferecerem elevada possibilidade de gerar conhecimento para entender, prevenir ou aliviar um problema que afete o bem-estar dos sujeitos da pesquisa e de outros indivíduos;

b) o risco se justifique pela importância do beneficio esperado;

c) o benefício seja maior, ou no mínimo igual, a outras alternativas já estabelecidas para a prevenção, o diagnóstico e o tratamento.

V.2 - As pesquisas sem benefício direto ao indivíduo devem prever condições de serem bem suportadas pelos sujeitos da pesquisa, considerando sua situação física, psicológica, social e educacional.

V.3 - O pesquisador responsável é obrigado a suspender a pesquisa imediatamente ao perceber algum risco ou dano à saúde do sujeito participante da pesquisa, conseqüente à mesma, não previsto no termo de consentimento. Do mesmo modo, tão logo constatada a superioridade de um método em estudo sobre outro, o projeto deverá ser suspenso, oferecendo-se a todos os sujeitos os beneficios do melhor regime.

V.4 - O Comitê de Ética em Pesquisa da instituição deverá ser informado de todos os efeitos adversos ou fatos relevantes que alterem o curso normal do estudo.
V.5 - O pesquisador, o patrocinador e a instituição devem assumir a responsabilidade de dar assistência integral às complicações e danos decorrentes dos riscos previstos.

V.6 - Os sujeitos da pesquisa que vierem a sofrer qualquer tipo de dano previsto ou não no termo de consentimento e resultante de sua participação, além do direito à assistência integral, têm direito à indenização.

V.7- Jamais poderá ser exigido do sujeito da pesquisa, sob qualquer argumento, renúncia ao direito à indenização por dano. O formulário do consentimento livre e esclarecido não deve conter nenhuma ressalva que afaste essa responsabilidade ou que implique ao sujeito da pesquisa abrir mão de seus direitos legais, incluindo o direito de procurar obter indenização por danos eventuais.

\section{VI - Protocolo de pesquisa}

O protocolo a ser submetido à revisão ética somente poderá ser apreciado se estiver instruído com os seguintes documentos, em português:

Vl.1 - Folha de rosto: título do projeto, nome, número da carteira de identidade, $\mathrm{CPF}$, telefone e endereço para correspondência do pesquisador responsável e do patrocinador, nome e assinaturas dos dirigentes da instituição e/ou organização;

VI.2 - Descrição da pesquisa, compreendendo os seguintes itens:

a) descrição dos propósitos e das hipóteses a serem testadas;

b) antecedentes científicos e dados que justifiquem a pesquisa. Se o propósito for testar um novo produto ou dispositivo para a saúde, de procedência estrangeira ou não, deverá ser indicada a situação atual de registro junto a agências regulatórias do país de origem;

c) descrição detalhada e ordenada do projeto de pesquisa (material e métodos, casuística, resultados esperados e bibliografia);

d) análise crítica de riscos e benefícios;

e) duração total da pesquisa, a partir da aprovação;

f) explicação das responsabilidades do pesquisador, da instituição, do promotor e do patrocinador;

g) explicitação de critérios para suspender ou encerrar a pesquisa;

h) local da pesquisa: detalhar as instalações dos serviços, centros, comunidades e instituições nas quais se processarão as várias etapas da pesquisa; 
i) demonstrativo da existência de infra-estrutura necessária ao desenvolvimento da pesquisa e para atender eventuais problemas dela resultantes, com a concordância documentada da instituição;

j) orçamento financeiro detalhado da pesquisa: recursos, fontes e destinação, bem como a forma e o valor da remuneração do pesquisador;

1) explicitação de acordo preexistente quanto à propriedade das informações geradas, demonstrando a inexistência de qualquer cláusula restritiva quanto à divulgação pública dos resultados, a menos que se trate de caso de obtenção de patenteamento; neste caso, os resultados devem se tornar públicos, tão logo se encerre a etapa de patenteamento;

m) declaração de que os resultados da pesquisa serão tornados públicos, sejam eles favoráveis ou não; e

n) declaração sobre o uso e a destinação do material e/ou dados coletados.

VI.3 - Informações relativas ao sujeito da pesquisa:

a) descrever as características da população a estudar: tamanho, faixa etária, sexo, cor (classificação do IBGE), estado geral de saúde, classes e grupos sociais, etc. Expor as razões para a utilização de grupos vulneráveis;

b) descrever os métodos que afetem diretamente os sujeitos da pesquisa;

c) identificar as fontes de material de pesquisa, tais como espécimens, registros e dados a serem obtidos de seres humanos. Indicar se esse material será obtido especificamente para os propósitos da pesquisa ou se será usado para outros fins;

d) descrever os planos para o recrutamento de indivíduos e os procedimentos a serem seguidos. Fornecer critérios de inclusão e exclusão;

e) apresentar o formulário ou termo de consentimento, específico para a pesquisa, para a apreciação do Comitê de Ética em Pesquisa, incluindo informações sobre as circunstâncias sob as quais o consentimento será obtido, quem irá tratar de obtê-lo e a natureza da informação a ser fornecida aos sujeitos da pesquisa;

f) descrever qualquer risco, avaliando sua possibilidade e gravidade;

g) descrever as medidas para proteção ou minimização de qualquer risco eventual. Quando apropriado, descrever as medidas para assegurar os necessários cuidados à saúde, no caso de danos aos indivíduos. Descrever também os procedi- mentos para monitoramento da coleta de dados para prover a segurança dos indivíduos, incluindo as medidas de proteção à confidencialidade; e

h) apresentar previsão de ressarcimento de gastos aos sujeitos da pesquisa. A importância referente não poderá ser de tal monta que possa interferir na autonomia da decisão do indivíduo ou responsável de participar ou não da pesquisa.

VI.4 - Qualificação dos pesquisadores: curriculum vitae do pesquisador responsável e dos demais participantes.

VI.5 - Termo de compromisso do pesquisador responsável e da instituição de cumprir os termos desta Resolução.

\section{VII - Comitê de Ética em Pesquisa - CEP}

Toda pesquisa envolvendo seres humanos deverá ser submetida à apreciação de um Comitê de Ética em Pesquisa.

VIl.1 - As instituições nas quais se realizem pesquisas envolvendo seres humanos deverão constituir um ou mais de um Comitê de Ética em Pesquisa - CEP, conforme suas necessidades.

VIl.2 - Na impossibilidade de se constituir CEP, a instituição ou o pesquisador responsável deverá submeter o projeto à apreciação do CEP de outra instituição, preferencialmente entre os indicados pela Comissão Nacional de Ética em Pesquisa (CONEP/MS).

VIl.3 - Organização - a organização e criação do CEP será da competência da instituição, respeitadas as normas desta Resolução, assim como o provimento de condições adequadas para o seu funcionamento.

VIl.4 - Composição - o CEP deverá ser constituído por colegiado com número não inferior a 7 (sete) membros. Sua constituição deverá incluir a participação de profissionais da área de Saúde, das Ciências Exatas, Sociais e Humanas, incluindo, por exemplo, juristas, teólogos, sociólogos, filósofos, bioeticistas e, pelo menos, um membro da sociedade representando os usuários da instituição. Poderá variar na sua composição, dependendo das especificidades da instituição e das linhas de pesquisa a serem analisadas.

VIl.5 - Terá sempre caráter multi- e transdisciplinar, não devendo haver mais que metade de seus membros pertencentes à mesma categoria profissional, participando pessoas dos dois sexos. Poderá ainda contar com consultores ad hoc, pessoas 
pertencentes ou não à instituição, com a finalidade de fornecer subsídios técnicos.

VII.6 - No caso de pesquisas em grupos vulneráveis, comunidades e coletividades, deverá ser convidado um representante, como membro ad hoc do $\mathrm{CEP}$, para participar da análise do projeto específico.

VII.7 - Nas pesquisas em população indígena deverá participar um consultor familiarizado com os costumes e tradições da comunidade.

VII.8 - Os membros do CEP deverão se isentar de tomada de decisão, quando diretamente envolvidos na pesquisa em análise.

VII.9 - Mandato e escolha dos membros - a composição de cada CEP deverá ser definida a critério da instituição, sendo pelo menos metade dos membros com experiência em pesquisa, eleitos pelos seus pares. A escolha da coordenação de cada comitê deverá ser feita pelos membros que compõem o colegiado, durante a primeira reunião de trabalho. Será de três anos a duração do mandato, sendo permitida recondução.

VIl.10 - Remuneração - os membros do CEP não poderão ser remunerados no desempenho desta tarefa, sendo recomendável, porém, que sejam dispensados nos horários de trabalho do comitê das outras obrigações nas instituições às quais prestam serviço, podendo receber ressarcimento de despesas efetuadas com transporte, hospedagem e alimentação.

VIl.11 - Arquivo - o CEP deverá manter em arquivo o projeto, o protocolo e os relatórios correspondentes, por 5 (cinco) anos após o encerramento do estudo.

VII.12 - Liberdade de trabalho - os membros dos CEPs deverão ter total independência na tomada das decisões no exercício das suas funções, mantendo sob caráter confidencial as informações recebidas. Deste modo, não podem sofrer qualquer tipo de pressão por parte de superiores hierárquicos ou pelos interessados em determinada pesquisa, devem isentar-se de envolvimento financeiro e não devem estar submetidos a conflito de interesse.

VII.13 - Atribuições do CEP:

a) revisar todos os protocolos de pesquisa envolvendo seres humanos, inclusive os multicêntricos, cabendo-lhe a responsabilidade primária pelas decisões sobre a ética da pesquisa a ser desenvolvida na instituição, de modo a garantir e resguardar a integridade e os direitos dos voluntários participantes nas referidas pesquisas; b) emitir parecer consubstanciado por escrito, no prazo máximo de 30 (trinta) dias, identificando com clareza o ensaio, documentos estudados e data de revisão. A revisão de cada protocolo culminará com seu enquadramento em uma das seguintes categorias:

- aprovado;

- com pendência: quando o Comitê considera o protocolo como aceitável, porém identifica determinados problemas no protocolo, no formulário do consentimento ou em ambos, e recomenda uma revisão específica ou solicita uma modificação ou informação relevante, que deverá ser atendida em 60 (sessenta) dias pelos pesquisadores;

- retirado: quando, transcorrido o prazo, o protocolo permanece pendente;

- não aprovado; e

- aprovado e encaminhado, com o devido parecer, para apreciação pela Comissão Nacional de Ética em Pesquisa - CONEP/MS, nos casos previstos no capítulo VIII, item 4.c;

c) manter a guarda confidencial de todos os dados obtidos na execução de sua tarefa e arquivamento do protocolo completo, que ficará à disposição das autoridades sanitárias;

d) acompanhar o desenvolvimento dos projetos através de relatórios anuais dos pesquisadores;

e) desempenhar papel consultivo e educativo, fomentando a reflexão em torno da ética na ciência;

f) receber dos sujeitos da pesquisa ou de qualquer outra parte denúncias de abusos ou notificação sobre fatos adversos que possam alterar o curso normal do estudo, decidindo pela continuidade, modificação ou suspensão da pesquisa, devendo, se necessário, adequar o termo de consentimento. Considerar-se como antiética a pesquisa descontinuada sem justificativa aceita pelo CEP que a aprovou;

g) requerer instauração de sindicância à direção da instituição em caso de denúncias de irregularidades de natureza ética nas pesquisas e, em havendo comprovação, comunicar à Comissão Nacional de Ética em Pesquisa - CONEP/MS e, no que couber, a outras instâncias; e

h) manter comunicação regular e permanente com a CONEP/MS.

VII.14 - Atuação do CEP:

a) a revisão ética de toda e qualquer proposta de pesquisa envolvendo seres humanos não poderá ser dissociada da sua análise científica. 
Pesquisa que não se faça acompanhar do respectivo protocolo não deve ser analisada pelo Comitê;

b) cada CEP deverá elaborar suas normas de funcionamento, contendo metodologia de trabalho, a exemplo de: elaboração das atas; planejamento anual de suas atividades; periodicidade de reuniões; número mínimo de presentes para início das reuniões; prazos para emissão de pareceres; critérios para solicitação de consultas de experts na área em que se desejam informações técnicas; modelo de tomada de decisão, etc.

\section{VIII - Comissão Nacional de Ética em Pesquisa (CONEP/MS)}

A Comissão Nacional de Ética em Pesquisa CONEP/MS é uma instância colegiada, de natureza consultiva, deliberativa, normativa, independente, vinculada ao Conselho Nacional de Saúde.

O Ministério da Saúde adotará as medidas necessárias para o funcionamento pleno da Comissão e de sua Secretaria Executiva.

VIII.1 - Composição: a CONEP terá composição multi- e transdisciplinar, com pessoas de ambos os sexos e deverá ser composta por 13 (treze) membros titulares e seus respectivos suplentes, sendo 5 (cinco) deles personalidades destacadas no campo da ética na pesquisa e na saúde e 8 (oito) personalidades com destacada atuação nos campos teológico, jurídico e outros, assegurando-se que pelo menos um seja da área de gestão da saúde. Os membros serão selecionados, a partir de listas indicativas elaboradas pelas instituições que possuem CEP registrados na CONEP, sendo que 7 (sete) serão escolhidos pelo Conselho Nacional de Saúde e 6 (seis) serão definidos por sorteio. Poderá contar também com consultores e membros ad hoc, assegurada a representação dos usuários.

VIII.2 - Cada CEP poderá indicar duas personalidades.

VIII.3 - O mandato dos membros da CONEP será de quatro anos com renovação alternada a cada dois anos, de sete ou seis de seus membros.

VIII.4 - Atribuições da CONEP: compete à CONEP o exame dos aspectos éticos da pesquisa envolvendo seres humanos, bem como a adequação e atualização das normas atinentes. A CONEP consultará a sociedade sempre que julgar necessário, cabendo-lhe, entre outras, as seguintes atribuições: a) estimular a criação de CEPs institucionais e de outras instâncias;

b) registrar os CEPs institucionais e de outras instâncias;

c) aprovar, no prazo de 60 dias, e acompanhar os protocolos de pesquisa em áreas temáticas especiais tais como:

- genética humana;

- reprodução humana;

- fármacos, medicamentos, vacinas e testes diagnósticos novos (fases I, II e III) ou não registrados no País (ainda que fase IV), ou quando a pesquisa for referente a seu uso com modalidades, indicações, doses ou vias de administração diferentes daquelas estabelecidas, incluindo seu emprego em combinações;

- equipamentos, insumos e dispositivos para a saúde novos, ou não registrados no País;

- novos procedimentos ainda não consagrados na literatura;

- populações indígenas;

- projetos que envolvam aspectos de biossegurança;

- pesquisas coordenadas do exterior ou com participação estrangeira e pesquisas que envolvam remessa de material biológico para o exterior; e

- projetos que, a critério do $\mathrm{CEP}$, devidamente justificado, sejam julgados merecedores de análise pela CONEP;

d) prover normas específicas no campo da ética em pesquisa, inclusive nas áreas temáticas especiais, bem como recomendações para aplicação das mesmas;

e) funcionar como instância final de recursos, a partir de informações fornecidas sistematicamente, em caráter ex-oficio ou a partir de denúncias ou de solicitação de partes interessadas, devendo manifestar-se em um prazo não superior a 60 (sessenta) dias;

f) rever responsabilidades, proibir ou interromper pesquisas, definitiva ou temporariamente, podendo requisitar protocolos para revisão ética, inclusive os já aprovados pelo CEP;

g) constituir um sistema de informação e acompanhamento dos aspectos éticos das pesquisas envolvendo seres humanos em todo o território nacional, mantendo atualizados os bancos de dados;

h) informar e assessorar o MS, o CNS e outras instâncias do SUS, bem como do governo e da so- 
ciedade, sobre questões éticas relativas à pesquisa em seres humanos;

i) divulgar esta e outras normas relativas à ética em pesquisa envolvendo seres humanos;

j) a CONEP juntamente com outros setores do Ministério da Saúde, estabelecerá normas e critérios para o credenciamento de Centros de Pesquisa. Este credenciamento deverá ser proposto pelos setores do Ministério da Saúde, de acordo com suas necessidades, e aprovado pelo Conselho Nacional de Saúde; e

1) estabelecer suas próprias normas de funcionamento.

VIII.5 - A CONEP submeterá ao CNS para sua deliberação:

a) propostas de normas gerais a serem aplicadas às pesquisas envolvendo seres humanos, inclusive modificações desta norma;

b) plano de trabalho anual;

c) relatório anual de suas atividades, incluindo sumário dos CEPs estabelecidos e dos projetos analisados.

\section{IX - Operacionalização}

IX.1 - Todo e qualquer projeto de pesquisa envolvendo seres humanos deverá obedecer às recomendações desta Resolução e dos documentos endossados em seu preâmbulo. A responsabilidade do pesquisador é indelegável. Indeclinável e compreende os aspectos éticos e legais.

IX.2 - Ao pesquisador cabe:

a) apresentar o protocolo, devidamente instruído ao CEP, aguardando o pronunciamento deste, antes de iniciar a pesquisa;

b) desenvolver o projeto conforme delineado;

c) elaborar e apresentar os relatórios parciais e final;

d) apresentar dados solicitados pelo CEP, a qualquer momento;

e) manter em arquivo, sob sua guarda, por 5 anos, os dados da pesquisa, contendo fichas individuais e todos os demais documentos recomendados pelo CEP;

f) encaminhar os resultados para publicação, com os devidos créditos aos pesquisadores associados e ao pessoal técnico participante do projeto; e g) justificar, perante o CEP, interrupção do projeto ou a não publicação dos resultados.

IX.3 - O Comitê de Ética em Pesquisa institucional deverá estar registrado junto à CONEP/MS.

IX.4 - Uma vez aprovado o projeto, o CEP passa a ser co-responsável no que se refere aos aspectos éticos da pesquisa.

IX.5 - Consideram-se autorizados para execução, os projetos aprovados pelo CEP, exceto os que se enquadrarem nas áreas temáticas especiais, os quais, após aprovação pelo CEP institucional deverão ser enviados à CONEP/MS, que dará o devido encaminhamento.

IX.6 - Pesquisas com novos medicamentos, vacinas, testes diagnósticos, equipamentos e dispositivos para a saúde deverão ser encaminhados do CEP à CONEP/MS e desta, após parecer, à Secretaria de Vigilância Sanitária.

IX.7 - As agências de fomento à pesquisa e o corpo editorial das revistas científicas deverão exigir documentação comprobatória de aprovação do projeto pelo CEP e/ou CONEP, quando for o caso.

IX.8 - Os CEPs institucionais deverão encaminhar trimestralmente à CONEP/MS a relação dos projetos de pesquisa analisados, aprovados e concluídos, bem como dos projetos em andamento e, imediatamente, aqueles suspensos.

\section{$X$ - Disposições transitórias}

X.1 - O Grupo Executivo de Trabalho - GET, constituído através da Resolução CNS 170/95, assumirá as atribuições da CONEP até a sua constituição, responsabilizando-se por:

a) tomar as medidas necessárias ao processo de criação da CONEP/MS; e

b) estabelecer normas para registro dos CEP institucionais.

X.2 - O GET terá 180 dias para finalizar as suas tarefas.

X.3 - Os CEPs das instituições devem proceder, no prazo de 90 (noventa) dias, ao levantamento e análise, se for o caso, dos projetos de pesquisa em seres humanos já em andamento, devendo encaminhar à CONEP/MS, a relação dos mesmos.

X.4 - Fica revogada a Resolução 01/88. 